\title{
Effect of TLR4 on the growth of SiHa human cervical cancer cells via the MyD88-TRAF6-TAK1 and NF-кB-cyclin D1-STAT3 signaling pathways
}

\author{
LI MA $^{1}$, LI FENG ${ }^{1}$, XIAOPING DING ${ }^{1}$ and YONGWANG LI ${ }^{2}$ \\ Departments of ${ }^{1}$ Obstetrics and Gynecology, and ${ }^{2}$ Anesthesiology, \\ The Second Artillery General Hospital, Beijing 100088, P.R. China
}

Received June 1, 2016; Accepted September 28, 2017

DOI: $10.3892 / \mathrm{ol} .2018 .7801$

\begin{abstract}
The present study aimed to investigate the effect of Toll-like receptor 4 (TLR4) on SiHa human cervical cancer cells and its potential molecular biological mechanisms. The expression of TLR4 following treatment with lipopolysaccharide (LPS) in in SiHa cervical cancer cells was detected by quantitative polymerase chain reaction (qPCR). LPS-induced cell proliferation and apoptosis were detected by MTT assay as well as staining with propidium iodide (PI) and Annexin V/PI double staining. qPCR was performed to analyze the expression levels of tumor necrosis factor receptor-associated factor 6 (TRAF6) and transforming growth factor-activated kinase 1 (TAK1) genes. Western blot analysis was performed to analyze the expression of myeloid differentiation 88 (MyD88), nuclear factor- $\kappa \mathrm{B}$ $(\mathrm{NF}-\kappa \mathrm{B})$, cyclin D1 and signal transducer and activator of transcription 3 (STAT3) proteins. In the present study, it was revealed that TLR4 expression in SiHa cervical cancer cells may be upregulated by LPS. Additionally, LPS was able to increase the proliferation of SiHa cells. However, LPS treatment did not have an effect on apoptosis of the cells. In addition, the MyD88-TRAF6-TAK1 and NF- $\kappa \mathrm{B}$-cyclin D1-STAT3 signaling pathways were induced in SiHa cells by LPS. These results suggested the effect of LPS and TLR4 on proliferation of $\mathrm{SiHa}$ human cervical cancer cells via the MyD88-TRAF6-TAK1 and NF- $\kappa$ B-cyclin D1-STAT3 signaling pathways.
\end{abstract}

Correspondence to: $\mathrm{Dr}$ Yongwang Li, Department of Anesthesiology, The Second Artillery General Hospital, 16 The New Street, Beijing 100088, P.R. China

E-mail: yongwangli286@163.com

Key words: Toll-like receptor 4, cervical cancer, myeloid differentiation primary response 88 , tumor necrosis factor receptor-associated factor 6 , transforming growth factor-activated kinase 1 , nuclear factor- $\kappa \mathrm{B}$

\section{Introduction}

Cervical cancer is one of the three most common types of malignant cancer of the female reproductive system, with the highest rates of mortality in gynecology (1). Surgery is the main therapeutic method for cervical cancer, assisted by chemotherapy, traditional Chinese medicine and biotherapy. The 5-year survival rate of cervical cancer is $\sim 20-30 \%$ (2). The major cause of the low survival rates may be due to high recurrence rates of $80 \%$, poor progression and tolerance to chemotherapy (3). As a first-line agent, paclitaxel serves an important role in the treatment of cervical cancer. Poor prognosis, high recurrence and metastasis is closely associated with resistance to taxol (4).

Toll-like receptors (TLRs) are type 1 transmembrane proteins, which can detect invasive pathogenic microorganisms and primarily exist in immune cells, including dendritic cells and macrophages (5). It was previously revealed that TLRs are closely associated with the progression of tumor (5). It has been demonstrated that tumor cells are able to promote its growth by employing TLR signal transduction processes (6). By stimulating inflammatory factors, particularly the activities of nuclear factor (NF)-kB, TLR ligands are able to facilitate tumor growth (7). Regarding ovarian tumors, it has been suggested that TLR2, TLR3, TLR4 and TLR5 have high levels of expression in normal ovarian epithelium and epithelial ovarian neoplasms (7). It was also revealed that TLR4 has a high expression level in ovarian granular cells (8).

Previous studies demonstrated that the TLR/myeloid differentiation 88 (MyD88) signaling pathway serves an essential role in taxol resistance $(9,10)$. Therefore, the TLR/MyD88a signaling pathway may be a novel direction to investigate how to prevent postoperative recurrence and chemotherapy tolerance and develop novel methods and targets.

TLR4, which is composed of an extra-cellular region, transmembrane domain and intra-cellular region, is a member of the tumor necrosis factor receptor superfamily (9). The TLR4 extra-cellular region includes a leucine-rich repeat sequence, which can promote adhesion among proteins and serves an important role in mediating interleukin (IL)-1-related protein kinase, MyD88 and tumor necrosis factor receptor-associated factor (TRAF) (10). The transmembrane domain of TLR4 is a structural region rich in cysteine. The intracellular region of 
TLR4 is similar to the structures of IL-1R (10). The present study aimed to investigate the effect of TLR4 on the growth of SiHa human cervical cancer cells and its adjuvant function on cervical cancer.

\section{Materials and methods}

Cell lines. SiHa human cervical cancer cells were purchased from The Cell Bank of Type Culture Collection of Chinese Academy of Sciences (Shanghai, China) and were cultured in Dulbecco's modified Eagle's medium (Gibco; Thermo Fisher Scientific, Inc., Waltham, MA, USA) supplemented with $10 \%$ fetal bovine serum (Fumeng Biotechnical Co., Ltd., Shanghai, China), $100 \mathrm{U} / \mathrm{ml}$ penicillin G (Sagon Inc., Shanghai, China) and $100 \mathrm{U} / \mathrm{ml}$ streptomycin (Sagon Inc.) at $37^{\circ} \mathrm{C}$ in $5 \% \mathrm{CO}_{2}$.

Cell proliferation test. Lipopolysaccharide (LPS; 1, 5, 10, 50 and $100 \mu \mathrm{g} / \mathrm{ml})$ was added to $\mathrm{SiHa}$ cells $\left(1 \times 10^{3}\right.$ cell/well) for 4, 6 and $8 \mathrm{~h}$ at $37^{\circ} \mathrm{C}$. Subsequently, $50 \mu \mathrm{l} \mathrm{MTT} \mathrm{(InvivoGen}$ Co., Ltd., Shanghai, China) was added to the cells for $4 \mathrm{~h}$ at $37^{\circ} \mathrm{C}$ in $5 \% \mathrm{CO}_{2}$. Dimethyl sulfoxide was added to the cells for $20 \mathrm{~min}$ at $37^{\circ} \mathrm{C}$. BioTek Elx800 ${ }^{\mathrm{TM}}$ microplate reader (BioTek Instruments, Inc., Winooski, VT, USA) was used for detection using a double wavelength at $490 \mathrm{~nm}$.

Cell apoptosis. LPS (10, 50 and $100 \mu \mathrm{g} / \mathrm{ml})$ was added to $\mathrm{SiHa}$ cells for $8 \mathrm{~h}$ at $37^{\circ} \mathrm{C}$. Alexa Fluor1 488 Annexin V/Dead Cell Apoptosis kit (Thermo Fisher Scientific, Inc.) was added to the cells, and the cells were incubated in the dark for $30 \mathrm{~min}$ at $37^{\circ} \mathrm{C}$. A FACSCalibur flow cytometer (BD Biosciences, Franklin Lakes, NJ, USA) was used to analyze apoptosis and analyzed using FlowJo 7.6.1 (Tree Star, Inc., Ashland, OR, USA).

Caspase-3 activity. LPS (10, 50 and $100 \mu \mathrm{g} / \mathrm{ml})$ was added to $\mathrm{SiHa}$ cells for $8 \mathrm{~h}$ at $37^{\circ} \mathrm{C}$. SiHa cells were washed once in ice-cold PBS and lysed in ice-cold lysis buffer (Beyotime Institute of Biotechnology, Haimen, China) for $30 \mathrm{~min}$ on ice. Protein concentration was determined using Enhanced BCA Protein Assay kit (Beyotime Institute of Biotechnology) according to the manufacturer's protocol, following centrifugation at $10,000 \times \mathrm{g}$ at $4^{\circ} \mathrm{C}$. A total of $30 \mu \mathrm{g}$ protein and Ac-DEVD-pNA were incubated for $2 \mathrm{~h}$ at $37^{\circ} \mathrm{C}$. A microplate reader (BioTek Elx800 ${ }^{\mathrm{TM}}$; BioTek Instruments, Inc.) was used for detection using a double wavelength of $405 \mathrm{~nm}$.

Reverse transcription-quantitative polymerase chain reaction $(R T-q P C R)$. Total RNA was isolated from SiHa cells induced with LPS using the NucleoSpin1 RNA II kit supplied by Machery-Nagel GmbH (Düren, Germany). The RevertAid ${ }^{\mathrm{TM}}$ First Strand cDNA Synthesis kit (VWR International, Darmstadt, Germany) was used to transcribe into cDNA according to the manufacturer's protocol $\left(37^{\circ} \mathrm{C}\right.$ for $1 \mathrm{~h}$ and $62^{\circ} \mathrm{C}$ for $\left.10 \mathrm{~min}\right)$. SYBR Green Master Mix (Applied Biosystems; Thermo Fisher Scientific, Inc.) was used for RT-qPCR to determine the relative levels of target mRNA for IL-6, tumor necrosis factor- $\alpha$ (TNF- $\alpha$ ) and monocyte chemoattractant protein-1 (MCP-1). PCR was performed in a three-step program as follows: $95^{\circ} \mathrm{C}$ for $20 \mathrm{sec}$, $60^{\circ} \mathrm{C}$ for $35 \mathrm{sec}$ and $72^{\circ} \mathrm{C}$ for $30 \mathrm{sec}$ for 40 cycles. Analysis of relative gene expression data was quantified using the $2^{-\Delta \Delta \mathrm{Cq}}$ method (11). The primers of target genes are presented in Table I.
Table I. The primers of target genes

Gene $\quad$ Primers (5'-3')

\begin{tabular}{ll}
\hline GAPDH & \\
Forward & ACGGATTTGGTCGTATTG \\
Reverse & GGAAGATGGTGATGGGATT \\
TAK1 & \\
Forward & AGCAAGTTCCTGCCACAAATGATA \\
Reverse & GCGGCGATCCTAGCTTCTATTTC \\
TRAF6 & TGATAGTGTGGGTGGAACTGC \\
Forward & CAGATGGGGCATTCATACTTG \\
Reverse & \\
IL-6 & GTGGAGATTGTTGCCATCAACG \\
Forward & CAGTGGATGCAGGGATGATGTTCTG \\
Reverse & \\
TNF- $\alpha$ & AACTTCTCCACAACCCTCTGC \\
Forward & AGATCCATGCCGTTGGCCAG \\
Reverse & \\
MCP-1 & GACATACTCCAAACCTTTCCAC \\
Forward & AACTTCTCCACAACCCTCTGC \\
Reverse & \\
\hline TAK1, transforming growth factor-activated kinase 1; TRAF6, tumor \\
necrosis factor receptor-associated factor 6; IL-6, interleukin-6; \\
TNF- $\alpha$, tumor necrosis factor- $\alpha$ MCP-1, monocyte chemoattractant \\
protein-1.
\end{tabular}

Western blot analysis. LPS $(10,50$ and $100 \mu \mathrm{g} / \mathrm{ml})$ was added to $\mathrm{SiHa}$ cells for $8 \mathrm{~h}$ at $37^{\circ} \mathrm{C}$. SiHa cells were washed once in ice-cold PBS and lysed in ice-cold lysis buffer (Beyotime Institute of Biotechnology) for $30 \mathrm{~min}$ on ice. Protein concentration was determined using Enhanced BCA Protein Assay kit (Beyotime Institute of Biotechnology) following centrifugation at $10,000 \mathrm{xg}$ at $4^{\circ} \mathrm{C}$. A total of $50 \mu \mathrm{g}$ protein was subjected to $8-12 \%$ SDS-PAGE and transferred to polyvinylidene fluoride membranes (Bio-Rad Laboratories, Inc., Hercules, CA, USA). The membranes were blocked with $5 \%$ bovine serum albumin (Beyotime Institute of Biotechnology) supplemented with TBST (0.1\% Tween-20; Beyotime Institute of Biotechnology) for 1 at $37^{\circ} \mathrm{C}$ and incubated with antibodies against MyD88 (sc-11356, 1:500, Santa Cruz Biotechnology, Inc., Dallas, TX, USA), NF-кB (cat. no. sc-7151; 1:500, Santa Cruz Biotechnology, Inc.), cyclin D1 (cat. no., sc-717; 1:500, Santa Cruz Biotechnology, Inc.), phosphorylated (p)-signal transducer and activator of transcription 3 (STAT3; cat. no., sc-8001-R; 1:500, Santa Cruz Biotechnology, Inc.) and GAPDH (cat. no., AF1186; Beyotime Institute of Biotechnology) at $4^{\circ} \mathrm{C}$ overnight followed by incubation with horseradish peroxidase-labeled Goat Anti-Rabbit IgG $(\mathrm{H}+\mathrm{L})$ secondary antibody (cat. no., A0208; dilution, 1:2,000; Beyotime Institute of Biotechnology) for $1 \mathrm{~h}$ at $37^{\circ} \mathrm{C}$. The protein blots were visualized using the enhanced chemiluminescence method (EMD Millipore, Billerica, MA, USA) and analyzed using Image_Lab_3.0 (Bio-Rad Laboratories, Inc.). 


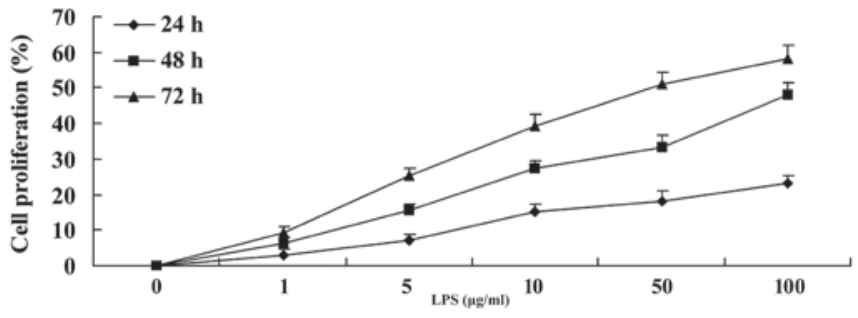

Figure 1. Cell proliferation analysis of lipopolysaccharide-stimulated SiHa cervical cancer cells.
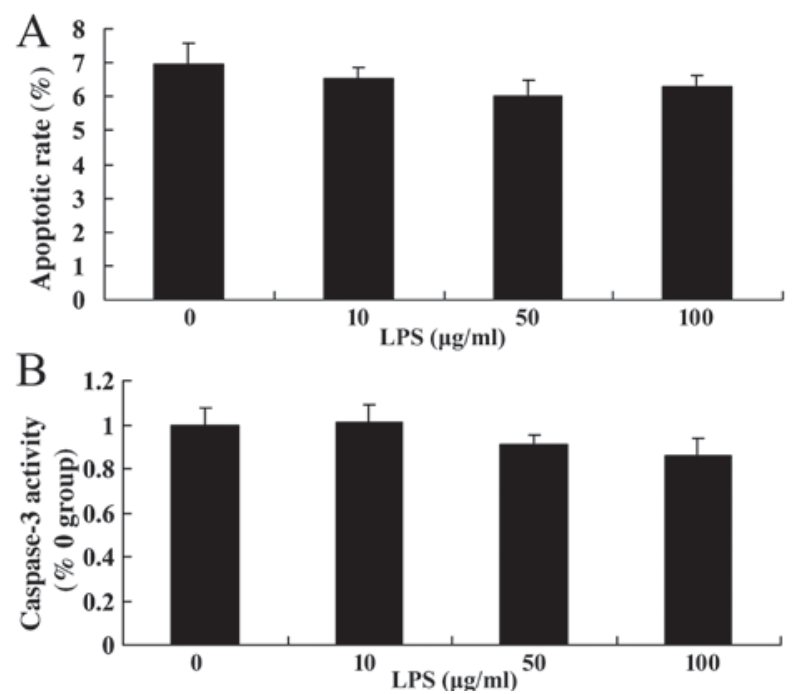

Figure 2. Analysis of apoptosis in LPS-stimulated SiHa cervical cancer cells (A) Apoptotic rate and (B) caspase-3 activity in SiHa cells that were stimulated by 10,50 and $100 \mu \mathrm{g} / \mathrm{ml}$ LPS. LPS, lipopolysaccharide.

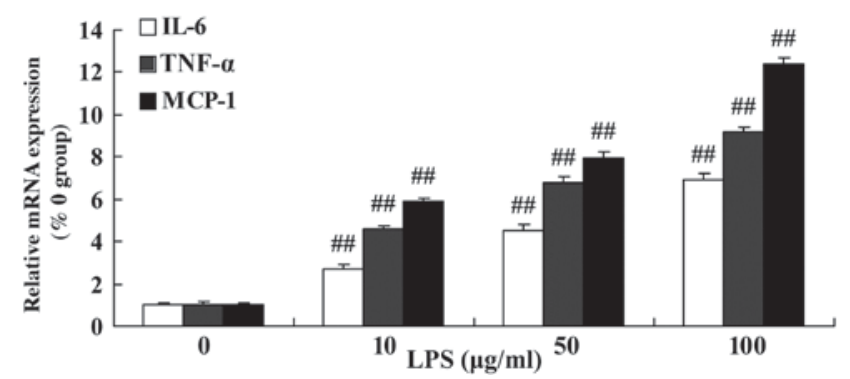

Figure 3. Inflammation in LPS-stimulated SiHa cervical cancer cells. The mRNA expression levels of IL-6, TNF- $\alpha$ and MCP-1 in SiHa cells that were by LPS. ${ }^{\# \#} \mathrm{P}<0.01$ compared with the control group $(0 \mu \mathrm{g} / \mathrm{ml}$ LPS $)$. IL-6, interleukin-6; TNF- $\alpha$, tumor necrosis factor- $\alpha$; MCP-1, monocyte chemoattractant protein-1.

Statistical analysis. All data are presented as the mean \pm standard deviation using SPSS 19.0 (IBM Corp., Armonk, NY, USA). All data comparisons were performed using one-way analysis of variance followed by Tukey's test. $\mathrm{P}<0.05$ was considered to indicate a statistically significant difference.

\section{Results}

Proliferation analysis of LPS-stimulated SiHa cervical cancer cells. To investigate whether LPS has an effect on the proliferation of SiHa cervical cancer cells, cell proliferation
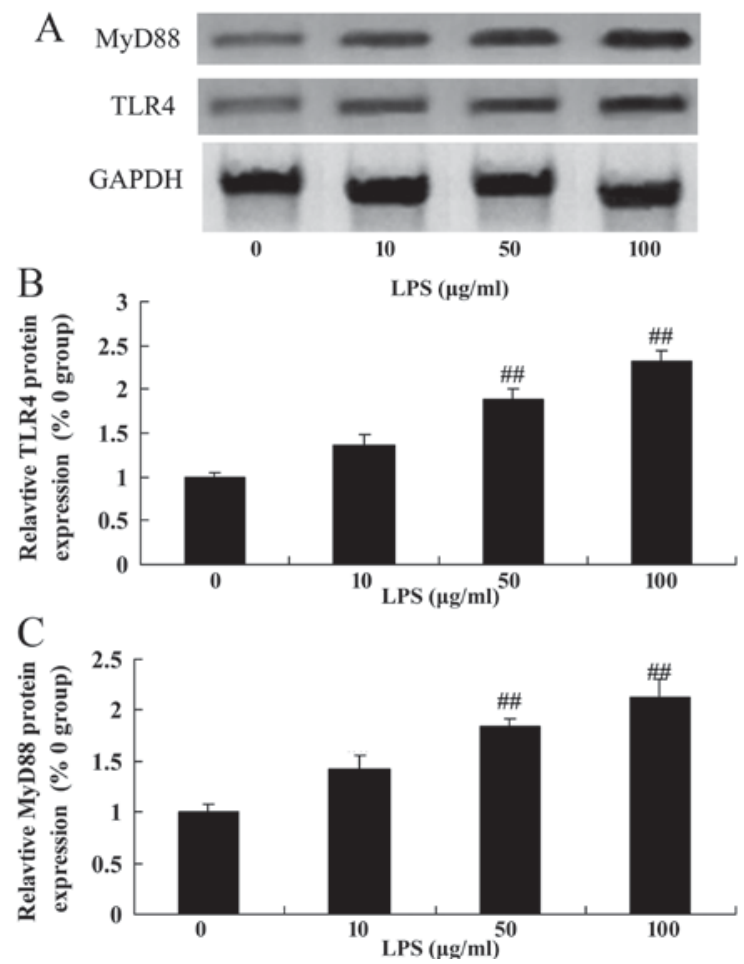

Figure 4. Level of TLR4 and MyD88 expression in SiHa cervical cancer cells may be upregulated by LPS. The level of (A) TLR4 and MyD88 proteins as determined by western blotting, and statistical analysis of the levels of (B) TLR4 and (C) MyD88 protein in SiHa cervical cancer cells. ${ }^{\# \#} \mathrm{P}<0.01$ vs. the control group ( $0 \mu \mathrm{g} / \mathrm{ml}$ LPS $)$. TLR4, toll-like receptor 4; LPS, lipopolysaccharide; MyD88, myeloid differentiation 88.

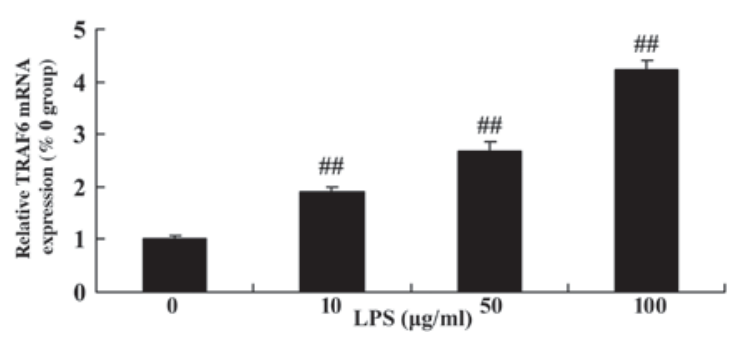

Figure 5. Expression of TRAF6 in LPS-stimulated SiHa cervical cancer cells. ${ }^{\# \#} \mathrm{P}<0.01$ vs. the control group $(0 \mu \mathrm{g} / \mathrm{ml}$ LPS $)$. TRAF6, tumor necrosis factor receptor-associated factor 6; LPS, lipopolysaccharide.

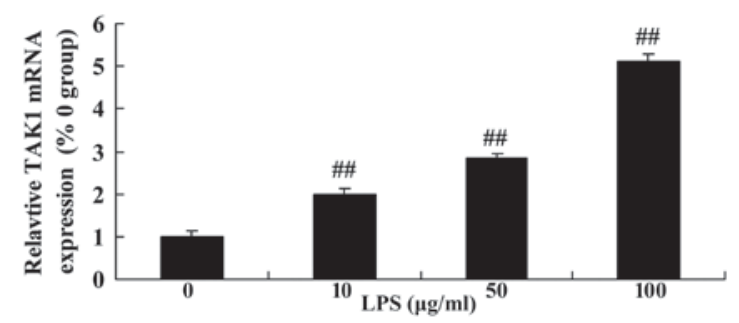

Figure 6. Expression level of TAK1 in LPS-stimulated SiHa cervical cancer cells. ${ }^{\# \#} \mathrm{P}<0.01$ vs. control group $(0 \mu \mathrm{g} / \mathrm{ml}$ LPS $)$. TAK1, transforming growth factor-activated kinase 1; LPS, lipopolysaccharide.

was evaluated by MTT assay. It was revealed that LPS was able to increase the proliferation of SiHa cervical cancer cells in a time- and dose-dependent manner compared with the control group ( $0 \mu \mathrm{g} / \mathrm{ml}$ LPS; Fig. 1$)$. 

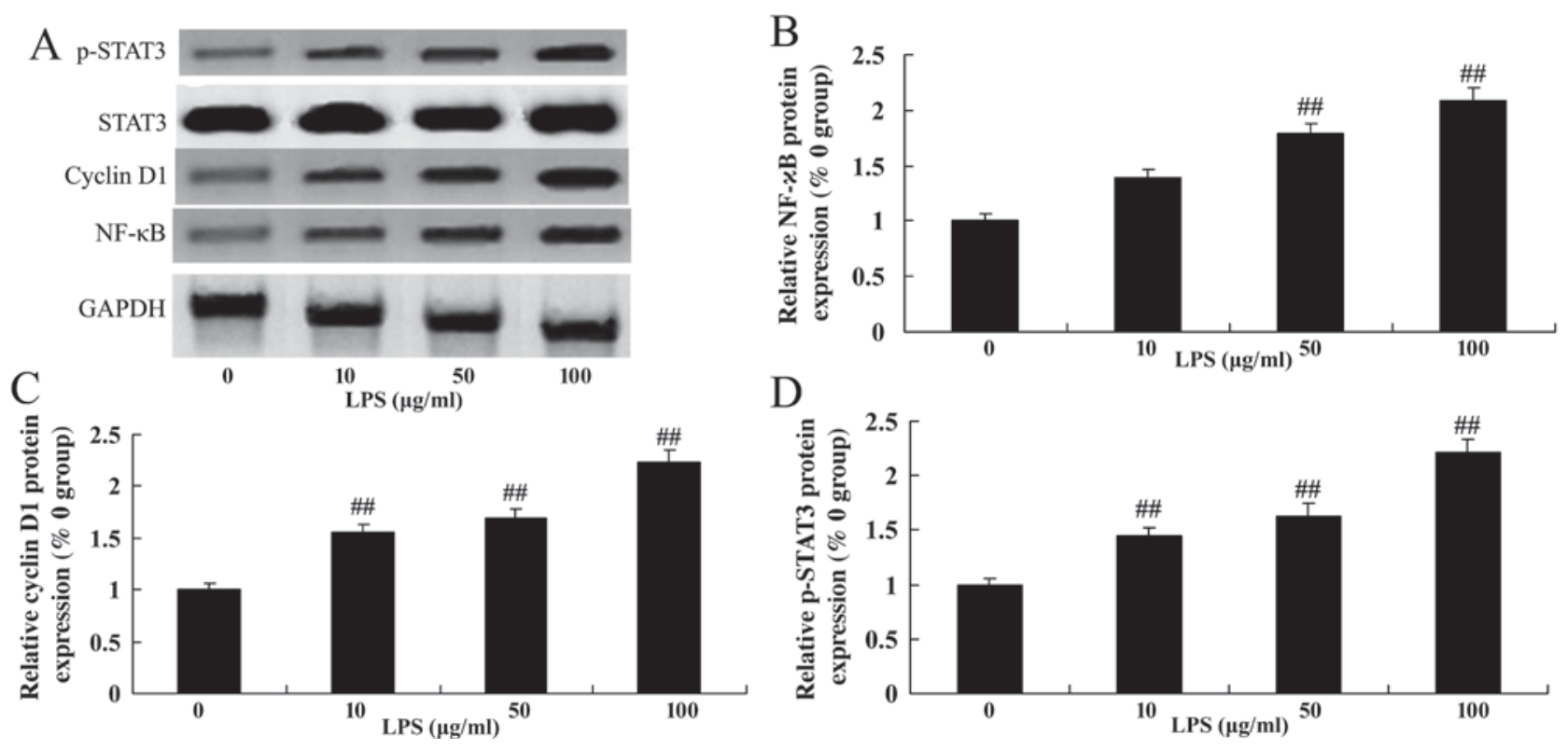

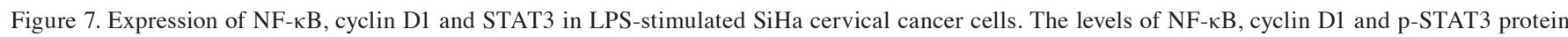
as analyzed by (A) western blotting, and statistical analysis of (B) NF-kB, (C) cyclin D1 and (D) p-STAT3 protein in SiHa cervical cancer cells. The levels

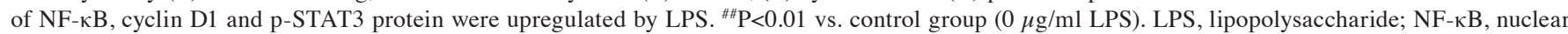
factor-kB; STAT3, signal transducer and activator of transcription 3.

Analysis of apoptosis of LPS-stimulated SiHa cervical cancer cells. The rate of apoptosis was determined following the stimulation of the cells with various doses of LPS by performing flow cytometry, and the activity of caspase- 3 was analyzed. It was indicated that LPS at various doses did not have an effect on apoptotic rate and caspase-3 activity in SiHa cells (Fig. 2), compared with the control group $(0 \mu \mathrm{g} / \mathrm{ml})$.

Inflammation in LPS-stimulated SiHa cervical cancer cells. The levels of mRNA expression of IL-6, TNF- $\alpha$ and MCP-1 were detected in SiHa cervical cancer cells following stimulation by LPS. As presented in Fig. 3, treatment with $10-100 \mu \mathrm{g} / \mathrm{ml}$ LPS was able to significantly increase the level of IL-6, TNF- $\alpha$ and MCP-1 mRNA in SiHa cells compared with the control group $(0 \mu \mathrm{g} / \mathrm{ml} \mathrm{LPS})$.

LPS may upregulate the levels of TLR4 and MyD88 expression in SiHa cervical cancer cells. The TLR4 signaling pathway, an important inflammatory signaling pathway, was evaluated by western blotting. Following treatment with various doses of LPS, it was revealed that treatment with $10-100 \mu \mathrm{g} / \mathrm{ml}$ LPS was able to markedly induce the level of TLR4 and MyD88 protein expression in $\mathrm{SiHa}$ cells compared with the control group (0 $\mu \mathrm{g} / \mathrm{m}$ LPS; Fig. 4).

Level of TRAF6 expression in LPS-stimulated SiHa cervical cancer cells. The levels of TRAF6 mRNA were detected following treatment of $\mathrm{SiHa}$ cells with various concentrations of LPS. Following the stimulation of SiHa cells with LPS, it was demonstrated that the level of TRAF6 mRNA expression was markedly upregulated compared with the control group (0 $\mu \mathrm{g} / \mathrm{ml}$ LPS; Fig. 5).

Level of transforming growth factor-activated kinase 1 (TAK1) expression in LPS-stimulated SiHa cervical cancer cells. In the present study, the levels of TAK1 expression were detected by RT-qPCR in SiHa cervical cancer cells following treatment with various concentrations of LPS. Fig. 6 revealed that the level of TAK1 mRNA expression was significantly upregulated by treatment with $10-100 \mu \mathrm{g} / \mathrm{ml}$ LPS in SiHa cells compared with the control group ( $0 \mu \mathrm{g} / \mathrm{ml}$ LPS).

Level of $N F-\kappa B$, cyclin D1 and p-STAT3 expression in LPS-stimulated SiHa cervical cancer cells. In addition, the expression level of NF- $\mathrm{B}$, cyclin D1 and STAT3 was detected by western blotting in cervical cancer $\mathrm{SiHa}$ cells that were treated with LPS. Treatment with LPS (50 and $100 \mu \mathrm{g} / \mathrm{ml}$ ) was able to significantly increase the level of NF- $\mathrm{B}$, cyclin D1 and p-STAT3 expression in SiHa cells compared with the control group (0 $\mu \mathrm{g} / \mathrm{ml}$ LPS; Fig. 7).

\section{Discussion}

The 5-year survival rates of cervical cancer are $\sim 30 \%$, which is a serious risk to the health and lives of females (12). Consequently, it has become a focus to investigate the occurrence, progression and metastasis of cervical cancer (12). In the present study, it was revealed that LPS increased cell proliferation but did not affect the rate of apoptosis and caspase-3 activity in $\mathrm{SiHa}$ cells.

TLR4 is a sub-type of TLRs. By activating immune cells, TLR is able to generate an endogenous or exogenous immune response (6). It has previously been demonstrated that TLR4 is closely associated with the occurrence and progression of tumors (6). A previous study revealed that TLR4 is expressed in various types of malignant cancer, including gastric carcinoma, hepatocellular carcinoma, prostatic cancer and lymphoma. In particular, genetic polymorphism of Asp299Gly of TLR4 is highly associated with the occurrence and progression of tumors (6). In addition, TLR4 serves a fundamental 
role in the apoptosis of tumor cells (9). By inhibiting apoptosis, TLR4 enhances the immune evasion of tumor cells. A previous study reported that TLR4 is positively expressed in epithelial ovarian cancer tissues or cell lines, which may provide a novel therapeutic target for treatment of cervical cancer (9). In the present study, LPS upregulated the expression of TLR4 protein in SiHa cells. These results indicated that TLR4 may mediate the growth of cervical cancer SiHa cells.

The TRAF6/TAK1 signaling pathway serves an important role in mechanisms of innate and acquired immunity (13). The TRAF6/TAK1 signaling pathway also participates in the immune response pathway mediated by TCR. A previous study suggested that the expression levels of TRAF6 correspond with those of TAK1 (13). By activating the immune modulatory pathways of $\mathrm{NF}-\kappa \mathrm{B}$ and mitogen-activated protein kinase (MAPK) and inducing the release of IL-6, TNF- $\alpha$ and interferon $-\alpha / \beta$, the activation of $B$ cells and the maturity and proliferation of $\mathrm{T}$ cells may be promoted by the TRAF6/TAK1 signaling pathway (13). Additionally, the TRAF6/TAK1 signaling pathway may participate in the regulation of the activation and maturation of dendritic cells (14). Therefore, antitumor immune functions can be induced (14). In the present study, it was revealed that treatment with LPS was able to significantly enhance IL-6, TNF- $\alpha$ and MCP-1 mRNA expression levels in SiHa cells.

Following binding with MyD88, members of the interleukin 1 receptor associated kinase (IRAK) family are recruited by TLRs, including IRAK1, IRAK2, IRAK4 and IRAK-M. Once IRAK4 is phosphorylated, it would separate from MyD88 and interact with TRAF6 (14). The binding of TAK1 leads to the activation of two downstream signaling pathways, including the I $\kappa \mathrm{B}$ kinase (IKK) complex and MAPK family. Composed of IKK-d, IxB, IKK-p and $\mathrm{IKK}-\mathrm{y} / \mathrm{NF}-\kappa \mathrm{B}$ essential modulator, IKK complex is able to catalyze the phosphorylation of the $\mathrm{I} \kappa \mathrm{B}$ protein $(14,15)$. This type of phosphorylation can trigger the degradation of IKBs and the activation of $\mathrm{NF}-\kappa \mathrm{B}$, as well as inducing the upregulation of anti-apoptosis. In the present study, it was revealed that treatment with LPS was able to significantly activate MyD88 protein expression and promote TRAF6 and TAK1 mRNA expression in SiHa cervical cancer cells. These results indicated that the effect of TLR4 on cervical cancer may be mediated by the MyD88-TRAF6-TAK1 signaling pathway. Zeng et al suggested that MC13 was able to protect against neuro-inflammatory injury through suppression of the TRAF6-TAK1-NF- $\kappa$ B signaling pathways (16).

TRAF is a multi-functional adaptor molecule in the cytoplasm. TRAF6 is an ubiquitin-ligating enzyme, which is able to activate TAK1 (17). TAK1 is a serine/threonine kinase, which is involved in various signal transduction pathways. Activated TAK1 is able to phosphorylate and activate the NF- $\kappa$ B-MAPK signaling transduction pathway and finally activate transduction factors, including $\mathrm{NF}-\kappa \mathrm{B}$ and adaptor protein complex-1 (18). The expression of TRAF6 and TAK1 were induced in malignant types of cancer and chronic or acute inflammatory diseases, including breast cancer, colorectal cancer, bone metastasis, lung injuries, rheumatoid arthritis and multiple sclerosis (19). In the present study, it was revealed that treatment with 50 and $100 \mu \mathrm{g} / \mathrm{ml}$ LPS was able to significantly induce $\mathrm{NF}-\kappa \mathrm{B}$ protein expression in SiHa cervical cancer cells.
Cyclin D1 and p27 protein serve a particular and interactive role in tumor progression and have certain implications for the evaluation of the progression, metastasis and prognosis of cancer (20). The $\mathrm{G}_{1} / \mathrm{S}$ checkpoint is the most important regulatory point in the cell cycle process. As a rate-limiting regulator in $\mathrm{G}_{1}$ cell cycle phase, a high level of cyclin D1 expression shortens the length of the $\mathrm{G}_{1}$ phase (21). The regulation of cyclin $D 1$ to $G_{1}$ phase is mediated by the regulation to phosphorylated retinoblastoma protein (22). The results of the present study indicated that the treatment with LPS significantly increased cyclin D1 protein expression in $\mathrm{SiHa}$ cells.

STAT3 with high degrees of phosphorylation do not exist in normal ovarian epithelial cells lines or benign ovarian tumor cell lines, and abnormal activation of the STAT3 signal transduction pathway may induce a malignant phenotype (23). Previous studies investigating the downstream target gene of the STAT3 transduction pathway have provided increasing evidence, which suggested that the STAT3 transduction pathway serves an important role in a number of processes, including overproliferation, inhibition of apoptosis, vascular reconstruction, invasion and metastasis and drug resistance (24). In addition, in the present study, it was revealed that treatment with LPS was able to significantly induce the expression of p-STAT3 protein in SiHa cells. Chen et al (22) demonstrated that treatment with Schizandrin A was able to suppress microglia-mediated neuron-inflammation via LPS-induced TRAF6-NF- $\kappa$ B and Jak2-Stat3 signaling.

In conclusion, the results of the present study demonstrated that treatment with LPS was able to effectively increase cell proliferation by regulating TLR4 expression in SiHa cells but did not have an effect on rate of apoptosis and caspase-3 activity. It was also indicated that TLR4 was able to regulate the growth of $\mathrm{SiHa}$ human cervical cancer cells via the MyD88-TRAF6-TAK1 and NF- $\mathrm{B}$-cyclin D1-STAT3 signaling pathways. The results suggest that TLR4 antagonists may be potential therapeutic agents for the treatment of human cervical cancer by modulating the MyD88-TRAF6-TAK1 and $\mathrm{NF}-\kappa \mathrm{B}$-cyclin D1-STAT3 signaling pathways, however further studies are required.

\section{References}

1. Symonds RP, Gourley C, Davidson S, Carty K, McCartney E, Rai D, Banerjee S, Jackson D, Lord R, McCormack M, et al: Cediranib combined with carboplatin and paclitaxel in patients with metastatic or recurrent cervical cancer (CIRCCa): A randomised, double-blind, placebo-controlled phase 2 trial. Lancet Oncol 16: 1515-1524, 2015.

2. Braicu EI, Fotopoulou C, Chekerov R, Richter R, Blohmer J, Kümmel S, Stamatian F, Yalcinkaya I, Mentze M, Lichtenegger W and Sehouli J: Role of serum concentration of VEGFR 1 and TIMP2 on clinical outcome in primary cervical cancer: Results of a companion protocol of the randomized, NOGGO-AGO phase III adjuvant trial of simultaneous cisplatin-based radiochemotherapy vs. carboplatin and paclitaxel containing sequential radiotherapy. Cytokine 61: 755-758, 2013.

3. Burtness B, Bourhis JP, Vermorken JB, Harrington KJ and Cohen EE: Afatinib versus placebo as adjuvant therapy after chemoradiation in a double-blind, phase III study (LUX-Head \& Neck 2) in patients with primary unresected, clinically intermediate-to-high-risk head and neck cancer: Study protocol for a randomized controlled trial. Trials 15: 469, 2014. 
4. Muwonge R, Wesley RS, Nene BM, Shastri SS, Jayant K, Malvi SG, Thara S and Sankaranarayanan R: Evaluation of cytology and visual triage of human papillomavirus-positive women in cervical cancer prevention in India. Int J Cancer 134 2902-2909, 2014.

5. DeCarlo CA, Rosa B, Jackson R, Niccoli S, Escott NG and Zehbe I: Toll-like receptor transcriptome in the HPV-positive cervical cancer microenvironment. Clin Dev Immunol 2012 785825, 2012.

6. Werner J, Decarlo CA, Escott N, Zehbe I and Ulanova M: Expression of integrins and Toll-like receptors in cervical cancer: Effect of infectious agents. Innate Immun 18: 55-69, 2012.

7. Li L, Cheng FW, Wang F, Jia B, Luo X and Zhang SQ: The activation of TLR7 regulates the expression of VEGF, TIMP1, MMP2, IL-6, and IL-15 in Hela cells. Mol Cell Biochem 389: 43-49, 2014.

8. Zhan Z, Xie X, Cao H, Zhou X, Zhang XD, Fan H and Liu Z: Autophagy facilitates TLR4- and TLR3-triggered migration and invasion of lung cancer cells through the promotion of TRAF6 ubiquitination. Autophagy 10: 257-268, 2014.

9. Xiao J, Guo Q, Wang X, Xie F, Zhang H and Sui L: Study on the expression and signification of TLR4/NO pathway in cervical tumorigenesis with high risk HPV infection. Zhonghua $\mathrm{Fu}$ Chan Ke Za Zhi 50: 41-47, 2015 (In Chinese)

10. $\mathrm{He} \mathrm{A}, \mathrm{Ji} \mathrm{R}$, Shao J, He C, Jin $\mathrm{M}$ and $\mathrm{Xu} \mathrm{Y}$ : TLR4-MyD88-TRAF6-TAK1 complex-mediated NF- $\kappa$ B activation contribute to the anti-inflammatory effect of V8 in LPS-induced human cervical cancer SiHa cells. Inflammation 39: 172-181, 2016.

11. Livak KJ and Schmittgen TD: Analysis of relative gene expression data using real-time quantitative PCR and the 2(-Delta Delta C(T)) method. Methods 25: 402-408, 2001.

12. Kirchheiner K, Nout RA, Czajka-Pepl A, Ponocny-Seliger E, Sturdza AE, Dimopoulos JC, Dörr W and Pötter R: Health related quality of life and patient reported symptoms before and during definitive radio (chemo)therapy using image-guided adaptive brachytherapy for locally advanced cervical cancer and early recovery-a mono-institutional prospective study. Gynecol Oncol 136: 415-423, 2015.

13. Tomomura M, Suzuki R, Shirataki Y, Sakagami H, Tamura $\mathrm{N}$ and Tomomura A: Rhinacanthin $\mathrm{C}$ inhibits osteoclast differentiation and bone resorption: Roles of TRAF6/TAK1/MAPKs/NF- $\mathrm{BB} / \mathrm{NFATc} 1$ signaling. PLoS One 10: e0130174, 2015.

14. He W and Cronstein BN: Adenosine A1 receptor regulates osteoclast formation by altering TRAF6/TAK1 signaling. Purinergic Signal 8: 327-337, 2012.
15. Bai C, Yang X, Zou K, He H, Wang J, Qin H, Yu X, Liu C, Zheng J, Cheng $F$ and Chen J: Anti-proliferative effect of RCE-4 from Reineckia carnea on human cervical cancer HeLa cells by inhibiting the PI3K/Akt/mTOR signaling pathway and NF- $\mathrm{BB}$ activation. Naunyn Schmiedebergs Arch Pharmacol 389: 573-584, 2016

16. Zeng KW, Yu Q, Liao LX, Song FJ, Lv HN, Jiang Y and Tu PF: Anti-neuroinflammatory effect of $\mathrm{MC13}$, a novel coumarin compound from condiment murraya, through inhibiting lipopolysaccharide-induced TRAF6-TAK1-NF-кB, P38/ERK MAPKS and Jak2-Stat1/Stat3 pathways. J Cell Biochem 116: 1286-1299, 2015.

17. Nees M, Geoghegan JM, Hyman T, Frank S, Miller L and Woodworth CD: Papillomavirus type 16 oncogenes downregulate expression of interferon-responsive genes and upregulate proliferation-associated and NF-kappaB-responsive genes in cervical keratinocytes. J Virol 75: 4283-4296, 2001.

18. Yang L, Gu L, Li Z and Zhou M: Translation of TRAF1 is regulated by IRES-dependent mechanism and stimulated by vincristine. Nucleic Acids Res 38: 4503-4513, 2010.

19. Capalbo G, Mueller-Kuller T, Koschmieder S, Klein HU, Ottmann OG, Hoelzer D and Scheuring UJ: Characterization of $\mathrm{ZC} 3 \mathrm{H} 15$ as a potential TRAF-2-interacting protein implicated in the NFKB pathway and overexpressed in AML. Int J Oncol 43: 246-254, 2013.

20. Wu Y, Fu H, Zhang H, Huang H, Chen M, Zhang L, Yang H and Qin D: Cyclin D1 (CCND1) G870A polymorphisms and cervical cancer susceptibility: A meta-analysis based on ten case-control studies. Tumour Biol 35: 6913-6918, 2014.

21. Ni HJ, Chang YN, Kao PH, Chai SP, Hsieh YH, Wang DH and Fong JC: Depletion of SUMO ligase hMMS21 impairs G1 to $\mathrm{S}$ transition in MCF-7 breast cancer cells. Biochim Biophys Acta 1820: 1893-1900, 2012.

22. Chen J, Bai M, Ning C, Xie B, Zhang J, Liao H, Xiong J, Tao X, Yan D, Xi X, et al: Gankyrin facilitates follicle-stimulating hormone-driven ovarian cancer cell proliferation through the PI3K/AKT/HIF-1 $\alpha /$ cyclin D1 pathway. Oncogene 35: 2506-2517, 2016.

23. Fan Z, Cui H, Yu H, Ji Q, Kang L, Han B, Wang J, Dong Q, Li Y, Yan Z, et al: MiR-125a promotes paclitaxel sensitivity in cervical cancer through altering STAT3 expression. Oncogenesis 5: e197, 2016.

24. Zhang P, Yang B, Yao YY, Zhong LX, Chen XY, Kong QY, Wu ML, Li C, Li H and Liu J: PIAS3, SHP2 and SOCS3 expression patterns in cervical cancers: Relevance with activation and resveratrol-caused inactivation of STAT3 signaling. Gynecol Oncol 139: 529-535, 2015. 